\title{
Peer Mediation Pilot Initiative in Castlerea Prison: A Process Evaluation
}

\section{Tanya Lalor}

\section{Abstract}

This paper details the development and outcomes of a pilot peer mediation initiative in Castlerea prison in County Roscommon, Ireland, in 2016-2017.

A process evaluation was undertaken using desk research and qualitative discussions with peer mediators and partners to the process. This pilot included a 10 -week training programme for peer mediators, the majority of whom were male Traveller prisoners in Castlerea prison. The partners to the programme are the Traveller Mediation Service (TMS), the Travellers in Prison Initiative (TPI) (see Appendix 1 for details of these services), The Irish Prison Service (IPS) and the Education and Training Board (ETB), called the „school” in Castlerea prison.

The paper describes the impacts and elements of good practice of the pilot programme, as well as proposed next steps in the programme's implementation. It concludes that the peer mediation programme has potential for implementation across Irish prisons.

\section{Keywords}

Mediation, Castlerea Prison, prison programme

\section{Introduction}

The Irish Traveller Movement (ITM) defines Travellers as:

An indigenous minority who, historical sources confirm, have been part of Irish society for centuries. Travellers" long shared history, cultural values, language, customs and traditions make them a self-defined group, and one which is recognisable and distinct. Their culture and way of life, of which nomadism is an important factor, distinguishes them from the sedentary (settled) population. (Irish Traveller Movement www.itmtrav.ie)

According to the All-Ireland Traveller Health Study (2010), there are 36,224 Travellers in the Republic of Ireland, with a further 3,905 in Northern Ireland.

Irish Travellers are one of the most marginalised and excluded groups in Irish society. According to the All-Ireland Traveller Health Study (AITHS: 2010), more than 2,700 Travellers do not have access 
to running water. The Traveller suicide rate is six times the national average for men and women. Traveller men are strongly over-represented in the Irish prison systems - while they account for approximately $0.7 \%$ of the total population (census 2016), approximately $15 \%$ of the male prison population are Travellers, according to the Irish Prison Service (IPS).

Castlerea prison is a closed, medium security prison for adult males. It is the committal prison for remand and sentenced prisoners in Connaught and also takes committals from counties Cavan, Donegal and Longford. The majority of inmates in Castlerea prison are believed to be Travellers. Conflict escalating into violence has been identified as an issue in Castlerea prison by both staff and prisoners. It can result in prisoners being placed on protection wings, which limits their access to prison-based services, and can have a detrimental impact on their health and wellbeing. Since 2009, the Irish Red Cross has worked with Travellers in prison to deliver workshops on conflict and violence. Arising from these, Travellers in Castlerea prison expressed an interest in further training to enable them to effectively and safely mediate in conflict situations.

In 2016, discussions between the Education and Training Board known as "the school" in Castlerea prison, the Traveller Mediation Service (TMS), the Travellers in Prison Initiative (TPI) and senior staff in Castlerea prison gave rise to a pilot peer mediation programme in Castlerea.

The Mediation Institute of Ireland (MII) describes mediation as ${ }^{a}$ voluntary process of conflict resolution that allows the parties in dispute the opportunity to address their issues in a confidential and private environment '.

The pilot started with a six-week training programme in peer mediation for prisoners in Autumn 2016 (3.5 hours per day, one day per week). It was designed and delivered by the TMS, in partnership with the prison "school", and was supported by the TPI and the IPS.

A total of 16 men graduated from the training (of whom 11 were Travellers), and the pilot peer mediation programme has subsequently been rolled out in the prison.

A second training programme has been developed for a further group of prisoners and discussions are underway for the further roll out of peer mediation across Irish prisons.

\subsection{Methodology}

A process "evaluation" was undertaken on the programme, which documented the programme as it unfolded, assessed its impacts, and made recommendations for the implementation of peer mediation in Castlerea and other Irish prisons. The methodology involved desk research, analysis of pilot programme data, interviews and focus groups, and attending meetings of the advisory group structure established to oversee the pilot.

\section{Peer mediation}

Peer mediation is a dispute resolution process in which a neutral mediator assists parties to a dispute to resolve it between them (Kaufer et al, 2014). By exchanging information, expressing feelings 
and listening to each other 's perception of the situation, parties are able to better understand another 's point of view (McWilliam et al, 2016). Mediators do not take sides or make decisions about solutions instead they help disputants to come up with an agreement of their own.

Peer mediation has its roots in the US and in schools in the late 1960s. One of its principles is that disputants can relate to the peer mediators better than to figures of authority. Kaufer et al (2014) describe its relevance to prisons:

"First, there is the issue of trust. Inmates are typically distrustful of authority, often for good reason. For many, the system has failed them repeatedly. Inmates often fear getting in trouble (either with other inmates or with prison staff) if they bring a conflict to the attention of the authorities. It can feel safer to reveal personal information to a peer than to an authority figure...Second, inmates understand prison culture and values. Inmates are far more likely to understand the complex social structures that exist within prisons and the types of conflicts that can arise as a result. This makes it easier for inmate mediators to understand which potential solutions are actually viable for the parties" (pp 195-196).

Peer mediation programmes often encounter scepticism from parties. Roeger (2003) states that staff in prisons "may see it as implying failure on the part of staff to successfully resolve prisoner disputes". However, she notes that mediation is rather a "matter of staff "holding back" and enabling prisoners in a way that helps the successful re-entry of prisoners into society". In Marion Correctional Institute in the US, prisoners reported initial suspicion of peer mediation, interpreting it as a prisonauthority-led initiative, but this changed as their involvement in the programme led to them believing that "we could openly share our problems and find our own solutions..."

Close and Lechman (1997) stress that those involved in the delivery of peer mediation should be involved in the planning and design of programmes, but also point to the importance of a "stringent training requirement".

Gauley (2006) refers to Emerson 's study (1990) which found that some peer mediators were not properly trained, were viewed as "policemen" and were frequently disliked by other students. Thus, the role and function of peer mediators should be clear and well understood.

Jason and Rhodes (1989) outlines benefits of peer mediation - peers serve as potential role models, create and reinforce norms that certain behaviours are not acceptable, and promote alternatives to those activities. The benefits of peer mediation were found to extend into the wider community and home settings, arising from the skills and experience of negotiation gained by peer mediators (Johnson, Johnson and Dudley, 1992). According to Kaufer et al (2014) prison- facilitated mediation empowers prisoners to address conflict and disputes before they escalate, and has the potential to reduce prison violence and lower recidivism in a cost-effective manner.

Haft and Weiss (1998) identified continuity, buy-in, administrative support, and "cheerleaders" (i.e. champions or those calling for support for a programme) as important requirements for success. 


\subsection{The 'Sorting It Out' prison programme}

This pilot programme was developed in a correctional facility in New South Wales, Australia. Its evaluation explored its impact not only in terms of the mediation and conflict coaching skills, but also in terms of how the programme itself could result in improved relations and a sense of "wellbeing" amongst staff and prisoners in the facility.

A six module training programme was attended by $78 \%$ of staff and $100 \%$ of eligible prisoners (39 staff and 21 inmates).

At the start of the programme, the evaluation examined perceptions about the degree of safety, cohesion between inmates, and "therapeutic hold" (perceptions of institutional support for inmate needs). Prisoners reported a higher rate of cohesion and safety, and staff perceived a higher perception of the degree of institutional support for inmate needs. At the end of the pilot, perceptions and views of all three (inmate cohesion, experienced safety, institutional support for inmates) had improved significantly for both inmates and staff (and was sustained after three months).

Staff perceptions of the extent of conflict in prison were greater than those of prisoners at the outset of the programme. By the end of the programme, staff perceptions of inmates' talking through disagreement had increased.

Staff responded positively to the programme: $92 \%$ said that they would use the skills to assist with disagreements, $62 \%$ said that they had used the skills, although a smaller proportion (21\%) reported using the specific mediation procedures acquired in workshops.

By the end of the programme, inmates were more aware of the efforts of staff in assisting with conflict; $61 \%$ of inmates reported they had used the skills learned to try to address issues, $80 \%$ said they would use mediation procedures acquired.

Inmates were overwhelming positive about the programme, and all participants said they would recommend it to others. The evaluators concluded that participants understood the programme to be primarily about community understanding of points of view and respectful listening and communication, rather than generating an actual solution to an issue. 


\subsection{The stages of mediation}

The model of mediation used in the Castlerea pilot was adapted by TMS from a schools' Peer Mediation Programme model. The design and development of the pilot was assisted by UK school Peer Mediation Trainer Rosemary Games. It involves a five step process, summarised below, and follows a problem-solving mediation approach (Spangler, B., 2003).

\section{Table 0.1 Summary of five step peer mediation}

\begin{tabular}{|c|l|}
\hline Stage & \multicolumn{1}{|c|}{ Examples } \\
\hline Introduction & $\begin{array}{l}\text { The mediator introduces him or herself and explains the mediation } \\
\text { promises and the rules. The mediator tries to make the disputants feel } \\
\text { comfortable. }\end{array}$ \\
\hline $\begin{array}{c}\text { Hearing the stories of the } \\
\text { disputants }\end{array}$ & $\begin{array}{l}\text { The mediator listens to each party describe the problem and reflects their } \\
\text { stories back to the disputants. }\end{array}$ \\
\hline Identifying feelings & $\begin{array}{l}\text { The disputants each describe how they feel about what happened, and the } \\
\text { mediator repeats back to the disputants (reflects back). }\end{array}$ \\
\hline Generating solutions & $\begin{array}{l}\text { The mediator asks both parties to brainstorm about how they might solve } \\
\text { the problem. The mediator notes down all the solutions but does not offer } \\
\text { the solutions themselves. In some instances, individual sessions with each } \\
\text { disputant and the mediator may be necessary. }\end{array}$ \\
\hline Both parties to the dispute agree a solution and the mediator confirms that \\
both agree to the solution.
\end{tabular}

\section{The Peer Mediation Pilot Programme in Castlerea}

- The initial six-week training programme included the following topics:

- Listening and communication

- The meaning of conflict

- Exploring Irish Traveller culture

- Exploring Traveller-related conflict

- Group work exploring the nature of conflict and its impact

- Personal responses to conflict, individual conflict styles and triggers

- Conflict escalation and de-escalation techniques

- Restorative practices in managing conflict and building relationships

- Role play 
Travellers were involved in delivering the sessions. Along with the TMS and the school, Travellers who were students of a mediation and conflict training programme, in partnership with the Kennedy Institute, Maynooth University (MU) facilitated the training.

21 participants started the training, 11 of whom were Travellers (52\%). Of the 21 participants, 16 (76\%) completed the training: Travellers accounted for 11 of these $(69 \%)$.

At the end of the six-week training (in November 2016), participants requested more training, and four additional weeks of role play and training in the practice of mediation was provided. In total, the programme provided 60 hours of training to the peer mediators, consistent with accredited training for Mediators Institute of Ireland (MII) accredited mediators.

Eight of the original participants took part in these sessions, and all but one was Travellers $(88 \%)$. An independent mediator, who was also a trainer accredited by the MII, then assessed the competencies of seven of the group of eight to determine their readiness to deliver peer mediation in the prison.Six passed their assessment (86\%), and five of these were Travellers (83\%). The high completion rate and Traveller participation rate is outlined in table 4.1 below.

\begin{tabular}{|c|c|c|c|c|c|c|}
\hline & $\begin{array}{l}\text { Started } \\
\text { course }\end{array}$ & $\begin{array}{c}\text { Completed } \\
\text { initial } 6 \\
\text { week } \\
\text { course }\end{array}$ & $\begin{array}{c}\text { Started } \\
\text { advanced } \\
\text { training }\end{array}$ & $\begin{array}{c}\text { Completed } \\
\text { advanced } \\
\text { training }\end{array}$ & $\begin{array}{c}\text { Underwent } \\
\text { assessment }\end{array}$ & $\begin{array}{c}\text { Passed } \\
\text { assessment }\end{array}$ \\
\hline Total participants & 21 & 16 & 8 & 8 & 7 & 6 \\
\hline Completion rate (all participants) & & $76 \%$ & & $100 \%$ & & $86 \%$ \\
\hline Number of Traveller participants & 11 & 11 & 7 & 7 & 6 & 5 \\
\hline $\begin{array}{c}\text { Travellers as a } \% \text { of all } \\
\text { participants }\end{array}$ & $52 \%$ & $69 \%$ & $88 \%$ & $88 \%$ & $86 \%$ & $83 \%$ \\
\hline Completion rate (Travellers) & & $100 \%$ & & $100 \%$ & & $83 \%$ \\
\hline
\end{tabular}

\subsection{Project outputs}

In March 2017, it was reported that at least 32 incidents were averted as a result of informal peer mediation undertaken: 31 conflict coaching sessions had been undertaken, and one formal successful referral to peer mediation was made. It was estimated that the peer mediation had impacted on 100 people, likely to result in a reduction in both conflict and prison sanctions. 


\subsection{The views of participants}

Focus groups were undertaken with participants at the outset of the programme, at the end of the first training phase, and following the end of training in March 2017 (undertaken by ETB staff). Feedback was also provided after each training session.

In the focus groups, the men spoke about how conflict in prison can easily arise, sometimes from small events ("it could be a dirty look") or at times when the outside world intersects with prison, such as when prisoners use telephones to contact family and loved ones. New committals or young prisoners can become involved in conflict, as there can be pressure in prison to appear "hard". Times of the year (summertime) and spaces (the yard) are associated with tension and conflict.

For Travellers, wider community issues (on the outside) such as family-related or long-running issues can result in prison conflict, which can — in turn — impact on the wider community and family members on the outside:

"Your name can bring you into it, then drag others into it...makes it bigger"

Participants noted that extreme violence such as stabbing is far lower in Castlerea than in other prisons, and space in prison, such as "the school", are a conflict-free and safe space (arising from the Red Cross programme). The men noted that informal conflict resolution took place in Castlerea, involving trusted and respected inmates.

\section{Objectives for the programme}

Participants had gained skills from the Red Cross programme and were keen to further develop these. Hopes for the programme included:

- "To make jail a safer place"

- "Certification and accreditation"

- "I want the prison officers to support it"

- "...prisoners training prisoners and peer to peer needs trust, and it can build trust."

Participants were also keen to support other Travellers to gain skills — within and outside of prison.

"I want to be able to run courses (like "train the trainer") at the end of this.

"I want to be able to develop skills and bring them back to my own community."

\section{Feedback from the training}

Participant evaluations through the training identified skills acquired:

- "Techniques to be able to bring parties together for mediation"

- "Learning to negotiate and communicate better..."

- "Knowing the difference between punitive ways and restorative ways of dealing with conflict"

- "Listening skills and understanding others" 
- "To learn how to handle different conflicts without the use of violence..."

- "Practicing how to mediate, thinking of what to say"

Aspects that were highly rated included discussions on Traveller culture, the causes of conflict, role-play and group work. Participants recommended continuous training in prison and delivery within the wider community:

- "Keep it running, it is very helpful, it would suit the young lads"

- "Further mediation courses and hopefully furthering our education"

- "Bring skills out into the community"

\section{Impacts of the training}

At the end of the first training phase, even though the men identified a need for more training, confidence levels had increased. They were not yet at the point where they could advance through the five stages of mediation, and were most comfortable at the stage of diffusing tension and de-escalation of conflict:

"Peer mediation is happening anyway...we just need more time in training"

"Six weeks is definitely too short...we need longer sessions"

Participants spoke about the respect shown to those taking part in mediation, and about how this in itself could result in a changed attitude towards conflict

"...because sometimes the respect shown would not be shown elsewhere."

The need to raise awareness of the programme was noted by the men. Some recommended a "meet and greet" type orientation between peer mediators and new committals to help them to avoid conflict and tension, and make them aware of the programme and of supports available.

\section{Impact of the pilot}

Three of the certified peer mediators spoke about the impacts of the training as the programme was being implemented. In terms of personal impacts:

"It has changed my view in that things can be talked out instead of conflict...I look at it in a different light"

"I'd look back and assess a situation before going in to try and stop it owhatever"

Suggested changes included opportunities for accreditation:

"I would like to see this programme being introduced as a Fetac Level 5 in the prison"

Prison impacts included

"A major impact, stopped getting people P19s [sanctions for breaches of prison discipline and rules], gives people an option... they go looking for peer mediators and they will assist them" 
"T think it has. We had our first peer mediation on paper a few weeks ago. It went very well"

"I think there is less violence than there was"

The impact on relationships between inmates and prison staff was regarded by one peer mediator as the most successful aspect of the programme

"People working together, prisoners and staff, a lot were bebind it"

The need for this to take place across the whole prison staff population was noted:

"...the officers on landings, it" $s$ alright the governors and chiefs knowing but it needs to filter down"

Awareness-raising was noted as an ongoing requirement:

"Maybe an open morning once a month to be informed of peer mediation"

"T" $d$ also like to see this programme being rolled out in all 14 prisons."

The programme also impacted on the wider community:

"We were able to prevent trouble starting on the inside and escalating to the outside"

Peer mediators were confident of the potential on the outside:

"... so mediators can further their mediation practice and hold down a job, stop them re-offending and coming back to prison"

"When I leave this place... turn a negative into a positive...say that my time in jail was used for something good"

Finally, the men spoke about the critical importance of having a Traveller organisation and Travellers leading out on the training:

"More Travellers will engage with the training if Travellers are involved in delivering it"

"Traveller prisoners liked that Traveller culture and conflict was part of the

course, and that the course was aimed at Travellers"

\section{Effectiveness of the programme and next steps}

\subsection{The methodology of the training}

Key points identified in the evaluation included the following:

- Three Traveller men were involved in delivering the programme: two were completing the Quality \& Qualifications Ireland (QQI) Level 5 and MII accredited mediation and conflict training programme with Maynooth University (MU), and one as an employee of TMS. This enabled a focus on Traveller identity and how conflict impacts on the Traveller community and key to the programme.

- After the first six weeks, additional resources were provided by TMS and the school to deliver additional training. The first six weeks were led by the TMS, with support from the school, then the school took the lead in the extended training period. 
- Graduates of the initial training received certificates at a ceremony attended by the prison governor, senior prison staff, the ETB, TMS and the TPI.

- The methodology was practical and inclusive, and potential barriers to participation, such as literacy, were overcome.

\subsection{The delivery of the wider peer mediation programme}

An advisory group provided oversight to the programme and met on a 4-6 weekly basis. It included senior prison staff (including governors), the Chaplain, TMS, the ETB, the IPS Psychologist, the TPI, and crucially, two representatives of peer mediator trainees (thus acknowledging their importance in the design and implementation of the programme). The structure was effective, addressed barriers in a clear and pragmatic manner, and crucially, the commitment of senior management was evident from the outset. Good practice aspects of the pilot are outlined in the table below:

Table 3.1 Evidence of good practice in the pilot programme

\begin{tabular}{|c|c|}
\hline Key component & Examples \\
\hline $\begin{array}{l}\text { Individuals resolve their } \\
\text { own disputes without } \\
\text { external intervention }\end{array}$ & $\begin{array}{l}32 \text { examples of mediation undertaken on an informal basis and } 1 \text { formal peer } \\
\text { mediation process has been undertaken shortly after start of programme. }\end{array}$ \\
\hline $\begin{array}{l}\text { Peer mediators are trusted } \\
\text { and respected by prisoners }\end{array}$ & Informal mediation reported by peer mediators. \\
\hline $\begin{array}{l}\text { Peer mediators viewed } \\
\text { negatively by prisoners }\end{array}$ & $\begin{array}{l}\text { Not evidenced to date but may remain a risk for peer mediators and should be } \\
\text { monitored. }\end{array}$ \\
\hline $\begin{array}{l}\text { Peer mediators should be } \\
\text { involved in planning and } \\
\text { implementing of } \\
\text { programmes }\end{array}$ & $\begin{array}{l}\text { The programme was responsive to the needs of the men, in terms of training } \\
\text { needs and consideration of implementation issues. The advisory group } \\
\text { involved the peer mediators. }\end{array}$ \\
\hline $\begin{array}{l}\text { Peer mediators should be } \\
\text { involved in the delivery of } \\
\text { training }\end{array}$ & $\begin{array}{l}\text { Students of mediation who were Travellers (MU) co-facilitated sessions. Four } \\
\text { peer mediators involved in the delivery of second training programme started } \\
\text { in March } 2017 .\end{array}$ \\
\hline $\begin{array}{l}\text { Buy-in, support and } \\
\text { commitment, monitoring } \\
\text { and evaluation }\end{array}$ & $\begin{array}{l}\text { An advisory group formed with multiple stakeholders, including senior prison } \\
\text { staff and representatives of the peer mediator trainees. Strong partnership, co- } \\
\text { operation and commitment of members. } \\
\text { Senior management has demonstrated commitment to the process. Wider } \\
\text { prison staff 'buy-in' needs to be developed. Raising awareness and future } \\
\text { training for prison officers will be required in future. }\end{array}$ \\
\hline
\end{tabular}




\begin{tabular}{|c|c|}
\hline Continuity and sustainability & $\begin{array}{l}\text { There will be a loss of peer mediators as prisoners are released, transferred or } \\
\text { burn out. The second training programme will provide succession and } \\
\text { additional peer mediators. } \\
\text { It is recommended that opportunities to link the programme with partners } \\
\text { outside of prison be explored, such as TMS, TPI, Traveller groups (to enable } \\
\text { the skills of the peer mediators to be used on release). This should also benefit } \\
\text { the prison system, as conflict from outside results in conflict in prison. }\end{array}$ \\
\hline Stringent training & $\begin{array}{l}60 \text { hours of training (and additional training) was provided as required. This } \\
\text { was supported by the School and TMS. } \\
\text { Peer mediators underwent a competency assessment with a MII accredited } \\
\text { mediator. } \\
\text { Support and debriefing for peer mediators through the Chaplain and the } \\
\text { school. } \\
\text { Potential for accredited training within prison (advanced mediator training) as } \\
\text { the project develops. }\end{array}$ \\
\hline $\begin{array}{l}\text { Building self-esteem, } \\
\text { empowerment, and learning } \\
\text { life-skills. }\end{array}$ & $\begin{array}{l}\text { The men report positive outcomes, including a good working relationship } \\
\text { between the prisoners and prison management, reflecting a potential for prison } \\
\text { community 'wellbeing' and positive wider community impacts (as reflected in } \\
\text { McWilliam et al). }\end{array}$ \\
\hline
\end{tabular}

\section{Considerations for implementing the programme}

\subsection{Determining the scope of mediation}

Criminality or breaches of prison discipline are considered as inappropriate referrals for mediation - there is a risk that peer mediation as a means of addressing prison discipline would undermine the voluntary nature of mediation, and also the independence of the peer mediators (who might be viewed as agents of the prison system of discipline). Likewise, exploitation or the use of power or intimidation are unsuitable for mediation, as it may prove difficult to maintain a neutral position in these circumstances. Mediation should be limited to inter-personal disagreement and as conflict in prison can arise from small events, the advisory group agreed that these should be the focus of mediation in its initial stages. The need to grade incidents for their suitability for mediation was identified.

\subsection{Practice issues and support}

Weekly practice meetings (for example, involving the school and prison Chaplain) with the peer mediators could provide support and de-briefing to mediators, and consider referrals for mediation. The TMS could provide ongoing support at key junctures. Monitoring safety issues for the mediator also needs to take place on an ongoing basis (a slow and cautious start to the programme was advised). 


\subsection{Sustaining the programme}

The turnover of prisoners, whether for reasons of release, or transfer, as well as the likely burden of mediation, will require a succession strategy. For example, it will be necessary to repeat the training of the programme on an ongoing basis with the support of existing peer mediators to sustain participation.

\subsection{Referrals to the programme}

Potential sources of referrals include:

- Observations by mediators of tension and conflictsituations

- $\quad$ Self-referrals by disputants and informal approaches

- Formal referrals: the advisory group agreed that the Chief Officer would be the initial referrer

Same-day mediation may be required following referral — this could be a challenge in a prison, and may require protocols.

\subsection{Recording incidents and outcomes}

During the training programme, staff of the school recorded incidents and their outcomes. A mechanism for ongoing recording of outcomes would be needed.

\subsection{Monitoring and oversight}

The advisory group will continue to review the progress of the roll out of the programme. It was recommended that involving some of the prison officers with the group would be considered, as they could act as champions of the service with other prison officers.

\subsection{Raising awareness and training for prison staff}

Raising awareness about the programme is important amongst prison staff and prisoners. The men designed posters, and it was agreed that these would be used as a means of raising awareness about the peer-mediation programme. In time, and once fully implemented, launch events and formal training for staff can be introduced. These should include induction training or workshops, as there is a need for clarity about the initiative and its scope and boundaries. There is also a clear need to manage expectations as to what it can achieve. 


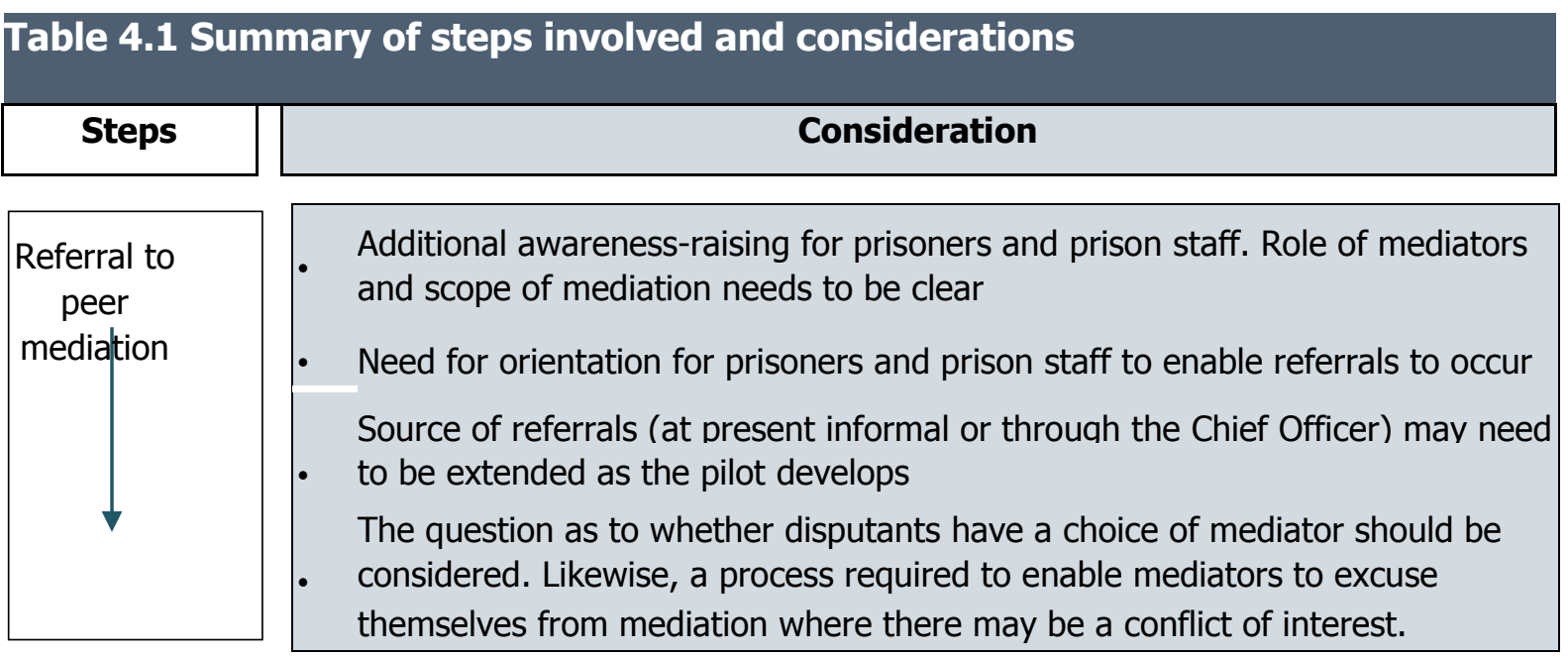

\begin{tabular}{|c|c|}
\hline $\begin{array}{l}\text { Review the } \\
\text { referral }\end{array}$ & $\begin{array}{l}\text { The group of mediators discuss the referral and its suitability for mediation } \\
\text { (with support). Frequency of meetings will need to be decided (weekly, twice } \\
\text { weekly or daily if required). Consideration as to what happens if a dispute } \\
\text { needs immediate resolution. For example, if referral is made once an issue } \\
\text { has already escalated). } \\
\text { - Grading of disputes to ascertain whether suitable for mediation required. } \\
\text { - Once a decision is made to accept the referral, a decision about who to } \\
\text { mediate (and whether there should be one or two mediators) needs to be } \\
\text { considered }\end{array}$ \\
\hline$\downarrow$ & \\
\hline $\begin{array}{l}\text { Secure } \\
\text { resources }\end{array}$ & $\begin{array}{l}\text { Before mediation occurs, space and time needs to be provided by prison } \\
\text { authorities. A clear protocol for this needed setting out when mediation can } \\
\text { occur, where, timing and exceptions to these principles. } \\
\text { As the sessions proceed, clarity for disputants and management } \\
\text { of expectations required (e.g. not all disputes will be resolved) }\end{array}$ \\
\hline
\end{tabular}

Review and monitoring of the process

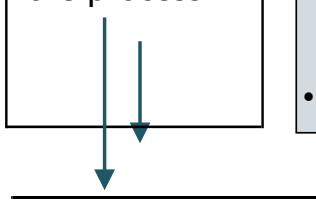

- Debriefing for mediators (at individual and group level) essential to identify risks, support reflective practice, and identify training and support needs

- Resources and commitment to be identified (how many hours per week are available for the process, what capacity for referrals)

Monitoring and recording of outcomes needed 
- Follow-up and review with prisoners about their understanding of the service and what it can offer

\section{Ongoing review - The advisory group should meet every 4 weeks initially and then every and oversight 6 weeks to review and monitor outcomes and issues.}

\section{Ongoing} support
- A support role on an ongoing basis around debriefing, follow-up and data collection required - in Castlerea this could be undertaken by the Chaplain and/or the ETB.

\section{Conclusions and next steps}

The initiative and its development have been very positive. It has been flexible in supporting the needs of the men through extending the training; it has involved the men in the programme implementation through the advisory group; commitment of prison, ETB, TMS staff and TPI has been demonstrated, and relationships of all parties involved has been positive.

A strong and pragmatic approach to rolling out the programme has been evidenced, characterised by consensus, close co-operation and strong partnership. Careful consideration has been given to the risks, as well as the opportunities, for the programme. The men have reported increased confidence in peer mediation and a sense of empowerment. The peer mediators have the support and respect of their peers in the prison. The pilot has generated interest amongst other prisoners, evidenced by work of the peer mediators as well as the interest in the second training programme (13 prisoners, eight of whom are Travellers up for the training). The graduates of the first programme are involved in the delivery of the second programme, as are the ETB and TMS.

As the programme develops, it will be important to capture the impacts on the peer mediators, the incidence of prison conflict but also the views and perceptions of the wider prison population (as well as the prison staff) about the programme, and the extent to which it can avert conflict and disputes, build relationships, community "wellbeing" and contribute to the overall rehabilitation environment.

Discussions around its application to other prisons have been initiated. A key provision in any roll out of the programme nationally will be to maintain Traveller involvement and mediation training expertise in its delivery. 


\section{References}

Census (2017). Census of Population 2016 - Profile 8 Irish Travellers, Ethnicity and Religion. Cork: CSO Close, C. L. \& Lechman, K. (1997). Fostering youth leadership: students train students and adults in conflict resolution. Theory into practise, 36(1), 1-7.

Gauley, M. (2006). Evaluation of Respectful Conflict Resolution and Peer Mediation Programme. Community University Institute for Social Research, University of Saskatchewan.

Haft, W.S \& Weiss, E.R. (1998). Peer Mediation in Schools: Expectations and Evaluations. Harvard Negotiation Law Review, Vol. 3, 213-319

Jason, L. \& Rhodes, J. (1989). Children helping children: Implications for prevention. Journal of primary prevention, 9, 203-11.

Johnson, D. W., Johnson, R. T., \& Dudley, B. (1992). Effects of peer mediation training on elementary school students. Conflict Resolution Quarterly, Volume 10, Issue 1, Autumn (Fall) 1992, pp 89-99

Kaufer, L., Noll, D. E., \& Mayer, J. (2014). Prisoner Facilitated Mediation: Bringing Peace to Prisons and Communities. Cardozo Journal of Conflict Resolution, 16:187219.

McWilliam, N, Nielsen, O., \& Moore, J. (2016). Sorting it out - A Community Mediation Training Program at a Therapeutic Prison. Sydney Law Review, Vol. 37, 1, pp 69-87

Roeger, D. (2003). Resolving Conflicts in Prison. Relational Justice Bulletin, Issue 19, November 2003

Spangler, B. (2003). Problem-Solving Mediation. Retrieved from

http://www.beyondintractability.org/essay/problem-solving mediation/

\section{Appendix 1}

The Traveller Mediation Service (formerly the Midlands Traveller Conflict Mediation Initiative — MTCMI) was established in 2009 and works in partnership with Travellers and others to help prevent conflict before it becomes serious; and also to intervene effectively where conflict is already an issue. The initiative is supported by Restorative Justice in the Community (RJC), funded by the Department of Justice and Equality, and hosted by the Health Services Executive (HSE). The service promotes and delivers conflict prevention and intervention skills training and capacity building to TMS stakeholders.

The TMS operates on the basis that the best people to resolve conflicts within the Traveller community were Travellers themselves, and it has provided specific training to enable Travellers to get the skills and knowledge to act as mediators in their own community. The TMS has collaborated with the Kennedy Institute, Maynooth University and Kildare Wicklow Education and Training Board (ETB) to develop a one year accredited training programme for Travellers in developing skills in mediation and conflict management. 
The Travellers in Prison Initiative (TPI) was developed in 2014 as a response to the particular needs and circumstances of Travellers within the 14 prisons in Ireland (and is funded by the St Stephen's Green Trust (SSGT), the Irish Prison Service and the Irish Probation Service).

The TPI has appointed an interagency Steering Group to guide its direction, and has identified five action areas: build a knowledge base about Travellers in prison; increase and improve access to prison-based services for Travellers; strengthen supports for families of Travellers in prison using a multiagency approach; strengthen self-identity and self-advocacy for Travellers in prison by mainstreaming a peer-support model, and increase awareness and capacity through training and learning programmes to prison service and probation service staff.

Tanya Lalor has spent more than 16 years undertaking consultancy work with community and voluntary sector organisations, many of which have included Traveller organisations. Her experience includes undertaking research, evaluation, preparing policy submissions, social enterprise business planning, and equality impact assessment.

She co-edited a book on social enterprise with Gerard Doyle, _Social Enterprise in Ireland - A People's Economy?‘ Published by Oak Tree Press in 2012. This book included contributions from leading social enterprise practitioners and academics and provided insights into a range of contemporary issues and themes which have an impact on the sector.

She has lectured on social enterprise and management for post-graduate programmes with Dublin Institute of Technology and for DCU (Ryan Academy). She holds a BA in Arts (Psychology), an MBS from the Graduate School of Business, UCD (Industrial Relations and Human Resource Management), and a Diploma in Social Integration and Enterprise for Community Development Workers, from the Centre for Co-operative Studies in UCC. 